\title{
Terracoccus luteus gen. nov., sp. nov., an LL-Diaminopimelic Acid-Containing Coccoid Actinomycete from Soil
}

\author{
HELMUT PRAUSER, ${ }^{1 *}$ PETER SCHUMANN,${ }^{1}$ FREDERICK A. RAINEY,${ }^{2}$ \\ REINER M. KROPPENSTEDT, ${ }^{2}$ AND ERKO STACKEBRANDT ${ }^{2}$ \\ DSMZ-German Collection of Microorganisms and Cell Cultures $\mathrm{GmbH}$, \\ D-07745 Jena ${ }^{1}$ and D-38124 Braunschweig, ${ }^{2}$ Germany
}

\begin{abstract}
A gram-positive, aerobic actinomycete was isolated from soil. Spherical cells of this organism occur singly or form packets, which may cluster. The diagnostic diamino acid of the cell wall peptidoglycan is LL-diaminopimelic acid. The predominate menaquinone is $\mathrm{MK-8}\left(\mathrm{H}_{4}\right)$, and the main fatty acids are 13-methyl tetradecanoic acid and 12-methyl tetradecanoic acid. The diagnostic polar lipids are phosphatidylethanolamine and phosphatidylinositol. The DNA base composition is $73 \mathrm{~mol} \% \mathrm{G}+\mathrm{C}$. Comparison of $16 \mathrm{~S}$ ribosomal DNA sequences showed that this isolate is a phylogenetic neighbor of Terrabacter tumescens and Intrasporangium calvum. Genotypic, chemotaxonomic, morphological, and physiological characteristics are used to describe a new genus and species, Terracoccus luteus gen. nov., sp. nov. The type strain is strain IMET 7848 (= DSM 44267).
\end{abstract}

The order Actinomycetales Buchanan 1917 was defined for gram-positive bacteria which produce mycelia or show at least a tendency to branch. The concept of the actinomycetes was extended on the basis of $16 \mathrm{~S}$ ribosomal DNA (rDNA) comparisons, which revealed a major phylogenetic lineage that included coccoid, sarcinoid, rodlike, coryneform, and nocardioform organisms, as well as organisms forming aerial mycelia and spores. A combination of chemotaxonomic properties supported the phylogenetic clustering of species at the genus level (35). Recently, the order Actinomycetales was emended, and its genera were classified in a hierarchic system on the basis of $16 \mathrm{~S}$ rDNA sequence comparisons (38).

Among the chemotaxonomic properties of the actinobacteria, the presence of particular diamino acids in position 3 of the peptide subunit of the peptidoglycan was shown to be a valuable taxonomic marker (31). One of these diagnostic diamino acids, LL-diaminopimelic acid ( $\left.L L-\mathrm{A}_{2} \mathrm{pm}\right)$, was found to be characteristic of genera that had been described early, i.e., Streptomyces (44), Intrasporangium (12), and Sporichthya (17). Recent descriptions have considerably increased the number of LL- $\mathrm{A}_{2}$ pm-containing genera, which include Nocardioides $(25$, 26), Terrabacter (2), Aeromicrobium (21), Luteococcus (42), Propioniferax (47), Microlunatus (24), and Friedmanniella (32). These genera represent five phylogenetic lineages $(32,38)$, and in addition to their 16S rDNA sequence differences, they differ from each other in chemotaxonomic, morphological, and physiological properties (32).

In the course of studies directed at isolating novel coryneform and nocardioform actinomycetes for biotechnological exploitation, the strain described here, strain IMET $7848^{\mathrm{T}}$, was isolated among other strains from a soil sample during the summer of 1985. The coccoid LL-A $\mathrm{A}_{2}$ pm-containing strain IMET $7848^{\mathrm{T}}$ was studied with respect to its cultural, morphological, physiological, and chemotaxonomic characteristics, its $16 \mathrm{~S}$ rDNA sequence, and its degree of DNA-DNA homology with related organisms. The organism was compared with previously described actinobacterial species and was found to represent a new species of a new genus.

* Corresponding author. Mailing address: DSMZ-Deutsche Sammlung von Mikroorganismen und Zellkulturen GmbH, Jena, Beutenbergstrasse 11, D-07745 Jena, Germany. Phone: 49364165 8528. Fax: 493641658527.

\section{MATERIALS AND METHODS}

Bacterial strains. A soil sample was taken from the bank of a duck pond at Kloster (the island of Hiddensee, Baltic Sea, Germany) directly at the water-soil interface, and it was immediately subjected to an isolation procedure in its natural condition. One gram of soil was suspended in $100 \mathrm{ml}$ of phosphate buffer, heavy particles were allowed to sediment, and the suspension was separated and then serially diluted with phosphate buffer; then $1 \mathrm{ml}$ of an appropriate concentration was mixed with $6 \mathrm{ml}$ of solubilized modified organic agar medium 79 ( $79 \mathrm{~m}$ ) (but with the agar concentration reduced to $0.6 \%$ [wt/vol]) at $48^{\circ} \mathrm{C}$, and the mixture was poured onto $79 \mathrm{~m}$ agar in petri dishes (diameter, $100 \mathrm{~mm}$ ). Plates showing about 50 colonies after 4 to 6 days of incubation at $28^{\circ} \mathrm{C}$ were used for isolation under a binocular microscope at low magnification.

Strains used for the phenotypic comparisons were the following type strains of the type species of the genera which were included in this study: Aeromicrobium erythreum NRRL B-3381 (= DSM 8599), Friedmanniella antarctica DSM 11053, Intrasporangium calvum 7 KIP (= DSM 43043), Janibacter limosus DSM 11140, Luteococcus japonicus IFO 12422 (= DSM 10546), Microlunatus phosphovorus JCM 9379 (= DSM 10555), Nocardioides albus IMET 7807 (= DSM 43109), Propioniferax innocua NCTC 11082 (= DSM 8251), Sanguibacter keddieii NCFB 3025 (= DSM 10542), Sporichthya polymorpha IMRU 3913 (= DSM 43042), Streptomyces albus ATCC 3004 (= DSM 40313), and Terrabacter tumescens NCIB 8914 (= DSM 20308).

Phages used to study phage-host relationships were Nocardioides sensu stricto phages X1 (= DSM 49101), X3 (= DSM 49102), and X5 (= DSM 49103); Nocardioides sensu lato phages X6 (= DSM 49135), X10 (= DSM 49104), and X24 (= DSM 49105); T. tumescens phages Tb1 (= DSM 49116) and Tb2 (= DSM 49158); Sporichthya polymorpha phage Sp1 (= DSM 49146); and Streptomyces phages S6 (= DSM 49150) and S7 (= DSM 49151). Information on these phages has been given previously (6).

Media. The following media were used in a liquid or a semisolid state (the latter achieved by the addition of $1.5 \%$ [wt/vol] Kobe 1 agar [Serva]): $79 \mathrm{~m}$ (32), $\mathrm{R}$ medium (46), enriched nutrient agar (Serva), Trypticase soy broth (TSB) medium (Difco), PYGV medium (39), and oatmeal agar (33). The first two media were used with and without the addition of vitamins according to a previously described prescription (39) at the concentration given for the PYGV medium.

Culture conditions. Growth and morphology on all of the media noted above were studied. The ranges of $\mathrm{pH}$ and of $\mathrm{NaCl}$ tolerance were determined on $\mathrm{R}$ agar, which was also used to prepare the inoculum for the physiological tests. The cell mass for the analyses of cell walls, mycolic acids, and polar lipids and for DNA extraction was produced on liquid $R$ medium. For the study of menaquinones, cells were cultured on liquid $79 \mathrm{~m}$ medium, and for the analysis of fatty acids, they were grown on TSB medium. The organisms were cultivated at $28^{\circ} \mathrm{C}$, on a horizontal shaker at $220 \mathrm{rpm}$, in $100-\mathrm{ml}$ bottles containing $20 \mathrm{ml}$ of the medium. The cells were harvested after $24 \mathrm{~h}$ for the menaquinone and fatty acid analyses and after $48 \mathrm{~h}$ for the other chemotaxonomic studies.

Phage-host relationship studies. Susceptibility to phages was studied on $79 \mathrm{~m}$ agar with double-layer agar plates by spotting high-titer phage suspensions (about $10^{10} \mathrm{phage} / \mathrm{ml}$ ) onto the top layer, which had been charged with cells of the strains to be tested. A strain under study was registered as susceptible to a particular phage if lysis occurred on a second plate containing the same strain after the transfer of material from a lytic zone of the first plate.

Morphological studies. Colony shape, cell morphology, and aggregate morphology were studied by bright-field microscopy and by phase-contrast micros- 
copy (oil immersion objective; magnification, $\times 100$ ) of material obtained from surface growth on agar plates or from liquid shaken culture, as well as by direct observation of growing cultures on the agar surface

Staining procedures. Gram staining and acid-fast staining were performed as described previously (16)

Physiological characterization. The temperature at which the physiological tests were performed was $28^{\circ} \mathrm{C}$ except for the studies of temperature range. The relationship to oxygen was studied by using stab cultures and agar slant cultures covered with paraffin oil. Oxidase activity was checked by examining the oxidation of $\mathrm{N}, \mathrm{N}, \mathrm{N}^{\prime}, \mathrm{N}^{\prime}$-tetramethyl-p-phenylenediamine dihydrochloride (34). Acid production from carbohydrates and alcohols was determined by the OF test as described previously (16). Utilization of organic acids as carbon sources and decomposition of xanthine, hypoxanthine, adenine, and DL-tyrosine were studied by previously described methods $(8,9)$. Catalase production was demonstrated on a slide by the production of bubbles immediately after a suspension of the organism was mixed with a drop of a $3 \%$ hydrogen peroxide solution. Urease activity, nitrate reduction, esculin hydrolysis, and hydrolysis of Tween 80 were studied by published methods (16). Decomposition of the emulsion of UVsterilized cinefilm strips incubated in phosphate buffer was used to verify gelatin hydrolysis. Casein hydrolysis was determined on streak-inoculated agar (a mixture of 3 volumes of liquefied distilled-water agar and 1 volume of steamed skim milk). DNA hydrolysis was determined on DNase Test Agar (Difco), and hydrolysis of starch was determined on inorganic salts-starch agar (33) after flooding of the agar surface with Lugol's solution $(0.1 \%$ [wt/vol] iodine and $0.2 \%$ [wt/vol] potassium iodide). $\mathrm{H}_{2} \mathrm{~S}$ production was determined as described previously (26). $\mathrm{NaCl}$ tolerance was checked by adding $\mathrm{NaCl}$ to $\mathrm{R}$ agar at final concentrations of 2,4 , and $10 \%$ (wt/vol). Additional carbon source utilization tests and enzyme tests were performed by previously described methods (13) which were modified as follows. The carbon source utilization test medium contained $6.7 \mathrm{~g}$ of yeast nitrogen base (Difco), $1.74 \mathrm{~g}$ of $\mathrm{K}_{2} \mathrm{HPO}_{4}$, and $0.36 \mathrm{~g}$ of $\mathrm{KH}_{2} \mathrm{PO}_{4}$ per liter. The enzyme test medium contained $0.05 \mathrm{M}$ Tris-HCl buffer, $0.5 \mathrm{~g}$ of Casamino Acids (Difco) per liter, and $0.5 \mathrm{~g}$ of yeast extract (Difco) per liter. The panels were inoculated with standardized bacterial suspensions in $0.9 \%$ (wt/vol) $\mathrm{NaCl}$ with turbidities of 0.5 to $1.0 \mathrm{McFarland}$ units and were subsequently incubated for $24 \mathrm{~h}$ at $28^{\circ} \mathrm{C}$. Then, $50 \mu \mathrm{l}$ of the filter-sterilized indicator solution was added to each of the auxanographic test wells and control wells. The indicator solution contained $4 \mathrm{mM}$ tetrazolium [3-(4,5-dimethylthiazol-2-yl)-2,5diphenyltetrazolium bromide] (MTT; a redox dye) (Sigma) and $4 \mathrm{mM}$ phenazine methosulfate (Sigma). The incubation was continued for $24 \mathrm{~h}$ in the dark. Formation of deep-blue-colored formazan indicated carbon source utilization (14). The auxanographic test results were read with a Multiscan MCC340 MKII photometer (Flow Laboratories, Meckenheim, Germany). The metabolization of a particular carbon source was considered to be positive if the following expression was fulfilled: $E_{540}$ (substrate being tested) $-E_{540}$ (control) $>0.129(15)$. The results of the enzyme tests were visually evaluated.

Chemotaxonomic characterization. Purified cell wall preparations were obtained as described previously (31). Amino acids and peptides of cell wall hydrolysates were analyzed by two-dimensional ascending thin-layer chromatography on cellulose plates, using solvent systems described previously (31). The molar ratios of cell wall amino acids were determined by gas chromatography (GC) and GC-mass spectrometry (GC-MS) of $n$-heptafluorobutyryl amino acid isobutyl esters (18). Cell wall sugars were identified as alditol acetates by GC-MS (10). The acyl type of peptidoglycan was determined by a previously described colorimetric method (43). Cellular fatty acids were extracted according to a published procedure (40) and were analyzed by GC (10). Menaquinone profiles were examined by high-performance liquid chromatography (37). Polar lipids were extracted as described previously (23) and were identified by two-dimensional thin-layer chromatography followed by spraying with specific reagents $(3)$. The absence of mycolic acids was demonstrated as described previously (22).

Analysis of DNA base composition and DNA-DNA hybridization. The $\mathrm{G}+\mathrm{C}$ content of the DNA was determined by high-performance liquid chromatography as described previously (10). For DNA-DNA hybridization, previously described methods (20) were used.

16S rDNA sequence determination and phylogenetic analysis. Genomic DNA extraction, PCR-mediated amplification of the 16S rDNA, and sequencing of the PCR products were performed as described previously (29). Significant overlap in the regions of adjacent primer targets existed, which resulted in the determination of almost the complete $16 \mathrm{~S}$ rDNA sequence. The sequence reaction products were electrophoresed by using a model 373A automatic DNA sequencer (Applied Biosystems, Foster City, Calif.). The 16S rDNA sequences were manually aligned with those of members of the order Actinomycetales by using the ae2 editor (19). Evolutionary distances for strain IMET $7848^{\mathrm{T}}$ and for a selection of actinobacterial species (data not shown) were calculated by a previously described method (11). Phylogenetic dendrograms were reconstructed by published methods $(5,30)$.

Nucleotide sequence accession numbers. The $16 \mathrm{~S}$ rDNA sequence of strain IMET $7848^{\mathrm{T}}$ (= DSM $44267^{\mathrm{T}}$ ) has been deposited in the EMBL database unde accession no. Y11928. The accession numbers for the sequences which were used in the construction of the phylogenetic tree are as follows: Aeromicrobium erythreum NRRL B-3381 ${ }^{\mathrm{T}}$, M37200; Arthrobacter globiformis DSM $20124^{\mathrm{T}}$, M23411; Cellulomonas flavigena DSM 20109 ${ }^{\mathrm{T}}$, X83799; I. calvum DSM 43043 ${ }^{\mathrm{T}}, \mathrm{Z}^{2} 8214$ J. limosus DSM $11140^{\mathrm{T}}$, Y08539; L. japonicus DSM 10546 ${ }^{\mathrm{T}}, \mathrm{Z} 78208$; Microbac- terium lacticum DSM 20427 ${ }^{\mathrm{T}}$, X77441; Microlunatus phosphovorus DSM $10555^{\mathrm{T}}$ Z78207; N. albus DSM 43109 ${ }^{\mathrm{T}}$, Z78213; Sanguibacter keddieii NCFB $3025^{\mathrm{T}}$ X79450; Sporichthya polymorpha DSM $46113^{\mathrm{T}}$, X72377; Streptomyces albidoflavus DSM 40455 , Z76676; and T. tumescens DSM 20308 ${ }^{\mathrm{T}}$, X83812. The $16 \mathrm{~S}$ rDNA sequence of Dermatophilus congolensis DSM 43037 was obtained from the Ribosomal Database Project (19)

\section{RESULTS}

Culture characteristics. Strain IMET $7848^{\mathrm{T}}$ grew well on agar media and in liquid shaken cultures. $\mathrm{R}$ medium, medium $79 \mathrm{~m}$, and TSB medium supported the growth of this organism. Growth on oatmeal agar was poor, and only traces of growth occurred on PYGV agar. The addition of vitamins did not influence growth. Visible growth appeared on optimal media after 24 to $48 \mathrm{~h}$ of incubation at $28^{\circ} \mathrm{C}$. Growth was less rapid at $20^{\circ} \mathrm{C}$, was very poor at 15 and $37^{\circ} \mathrm{C}$, and was lacking at 10 and $45^{\circ} \mathrm{C}$. The optimal $\mathrm{pH}$ was 6.0 to 7.2 . At $\mathrm{pH} 4.5$ and 9.5, growth was sparse. In stab cultures, growth occurred only at the surface. No growth was observed on agar slant cultures covered with paraffin oil. The color of the colonies was yellow with a slight tendency toward orange. Two forms of colonies were seen on agar plates at various numerical proportions: (i) rough, irregularly raised, lobed colonies (Fig. 1A); and (ii) smooth, convex, circular colonies (Fig. 1B). The colonies varied from $0.05 \mathrm{~mm}$ (if densely grouped) to $2.0 \mathrm{~mm}$ (if widely spaced) in diameter.

Maintenance. Serial transfers at 4-week intervals followed by maintenance at $4^{\circ} \mathrm{C}$, freeze-drying, and maintenance in the vapor phase above liquid nitrogen were suitable provisions for preservation.

Phage-host relationships. Strain IMET $7848^{\mathrm{T}}$ was not susceptible to any of the phages used in this study.

Morphological characteristics. On $\mathrm{R}$ agar plates incubated at $28^{\circ} \mathrm{C}$, the cells of strain IMET $7848^{\mathrm{T}}$ were spherical or nearly spherical and ranged from 0.7 to $1.3 \mu \mathrm{m}$ in diameter (Fig. 1C). The cells of smooth colonies occurred singly, in pairs, in tetrads, or in small irregular clusters (Fig. 1C). Upon direct inspection, the cells of rough colonies on agar plates were found to be mostly arranged in more or less regular packets which resulted from cell divisions in three perpendicular planes (Fig. 1D). As a rule, the packets adhered to one another, forming clusters (Fig. 1D). Formation of spores and cell motility were not observed.

Staining reactions. Strain IMET $7848^{\mathrm{T}}$ stained gram positive, and no lysis was observed following treatment with $3 \%$ (wt/vol) $\mathrm{KOH}$. The cells were not acid fast.

Physiological characteristics. Strain IMET $7848^{\mathrm{T}}$ grew only in the presence of air. The oxidase test was negative. Catalase, urease, and $\mathrm{H}_{2} \mathrm{~S}$ were produced. Nitrate was not reduced to nitrite. Acid was not produced from any of the tested substrates (D-ribose, L-arabinose, D-xylose, L-rhamnose, D-glucose, D-fructose, D-mannose, D-galactose, maltose, lactose, sucrose, D-trehalose, D-raffinose, adonitol, dulcitol, myo-inositol, Dmannitol, and D-sorbitol). Starch, casein, gelatin, esculin, and DNA were hydrolyzed. Tween 80 was not hydrolyzed. Sodium acetate, sodium formate, sodium aconitate, sodium benzoate, sodium citrate, disodium succinate, and potassium hydrogen tartrate were not utilized. Xanthine, hypoxanthine, adenine, DL-tyrosine, and sodium hippurate were not decomposed. The MTT reduction tests showed that strain IMET $7848^{\mathrm{T}}$ utilized D-arabitol, gluconate, $N$-acetyl-D-glucosamine, $m y o$-inositol, L-proline, succinate, sucrose, and D-turanose. Utilization of acetamide, L-alanine, 4-aminobutyrate, L-aspartate, benzoate, 3-hydroxybenzoate, 4-hydroxybenzoate, caprate, citrate, D-glucosaminic acid, D-glucuronate, 2-oxoglutarate, L-leucine, phenylacetate, pimelate, putrescine, quinate, L-rhamnose, D-ri- 

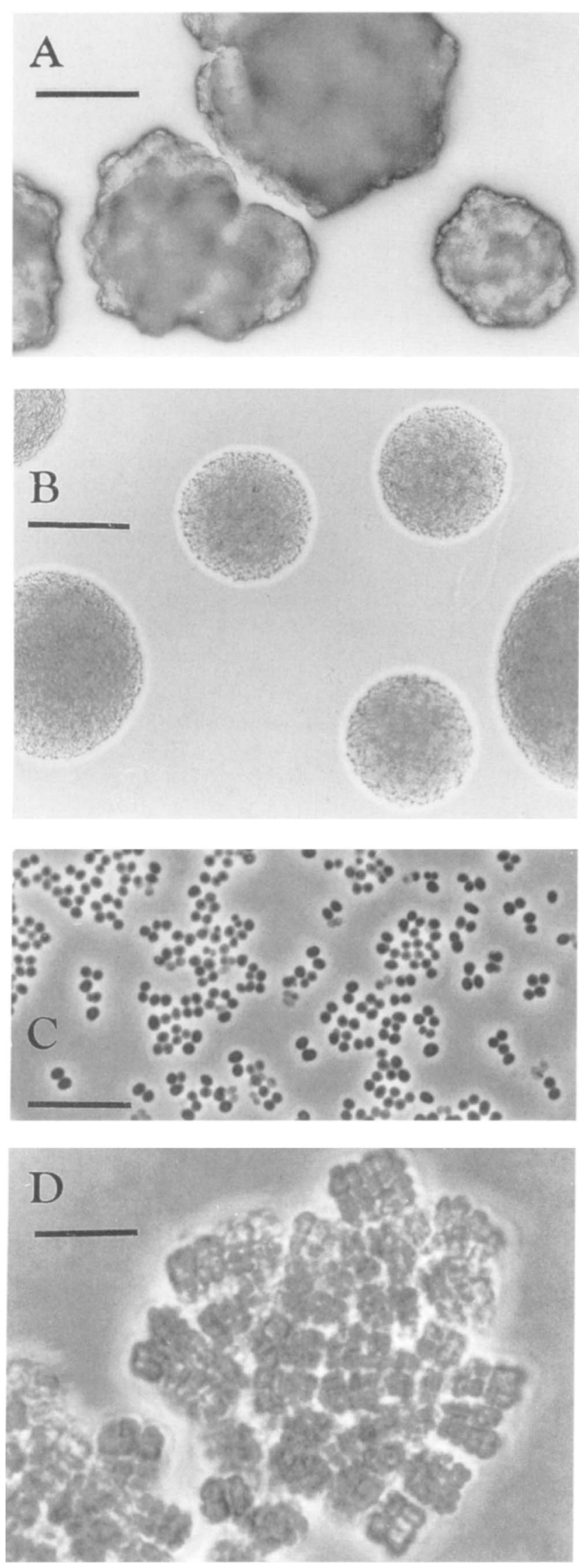

bose, L-serine, tyramine, 2-hydroxyvalerate, and L-valine was not observed. Strain IMET $7848^{\mathrm{T}}$ hydrolyzed all of the applied chromogenic substrates, i.e., $p$-nitrophenyl- $\beta$-D-xyloside, $p$-nitrophenylphosphorylcholine, and 2-deoxythymidine-5- $p$-nitrophenyl phosphate.

Chemotaxonomic characteristics. The peptidoglycan of strain IMET $7848^{\mathrm{T}}$ contained LL-A $2 \mathrm{pm}$. The molar ratio of the peptidoglycan amino acids Gly, Ala, Glu, and LL-A ${ }_{2}$ pm was 3.6:1.5:1.0:0.9. From this ratio and from the occurrence of typical peptides in partial hydrolysates (data not shown), it follows that the peptidoglycan represents the variation $\mathrm{A} 3 \gamma$ with three glycine residues as an interpeptide bridge (31). On the same basis, it was concluded that a fourth glycine residue is bound to the $\alpha$-carboxyl group of $\mathrm{D}$-glutamic acid in position 2 of the peptide subunit (peptidoglycan type A41.2 [6]). In the present study, binding of glycine to glutamic acid in position 2 was also demonstrated for I. calvum, as had been seen previously (32). The acyl type was acetyl. The isoprenoid quinones were represented by $\mathrm{MK}-8\left(\mathrm{H}_{4}\right)$ and $\mathrm{MK}-8\left(\mathrm{H}_{2}\right)$ at a peak area ratio of $34: 18$. The fatty acid profile was distinctly dominated by 13-methyl tetradecanoic acid and 12-methyl tetradecanoic acid, with minor amounts of hexadecanoic acid and 14-methyl hexadecanoic acid (Table 1). Diagnostic polar lipids were phosphatidylinositol and phosphatidylethanolamine, in addition to phosphatidylglycerol and diphosphatidylglycerol. Mycolic acids were absent. Whole-cell sugars were, in order of decreasing amounts, rhamnose, ribose, galactose, glucose, and mannose.

DNA base composition. The DNA base composition was 73 $\mathrm{mol} \% \mathrm{G}+\mathrm{C}$.

DNA-DNA hybridization. The percent DNA-DNA homology was $38.8 \%$ for strains IMET $7848^{\mathrm{T}}$ and $I$. calvum DSM $43043,36.45 \%$ for strains IMET $7848^{\mathrm{T}}$ and $T$. tumescens DSM 20308 , and $52.7 \%$ for the $I$. calvum and $T$. tumescens strains.

16S rDNA sequence analysis. An almost complete $16 \mathrm{~S}$ rDNA sequence comprising 1,476 nucleotides ( $>95 \%$ of the Escherichia coli sequence [1]) was determined for strain IMET $7848^{\mathrm{T}}$. A total of 1,322 nucleotides present in all of the strains between positions 41 and 1458 ( $E$. coli positions [1]) were used for comparative analysis. The $16 \mathrm{~S}$ rDNA sequence correspondence values were $97.6 \%$ for the strain pair IMET $7848^{\mathrm{T}}$ and T. tumescens, $97.1 \%$ for the strain pair IMET $7848^{\mathrm{T}}$ and $I$. calvum, and $97.1 \%$ for the strain pair T. tumescens and I. calvum. The phylogenetic dendrogram (Fig. 2) shows that J. limosus and Sanguibacter keddieii are less closely related to the aforementioned three organisms than they are to each other. The clusterig of strain IMET $7848^{\mathrm{T}}$, T. tumescens, I. calvum, J. limosus, and Sanguibacter keddieii is supported by bootstrap values of greater than $83 \%$. The relationship between strain IMET $7848^{\mathrm{T}}$ and $T$. tumescens is supported by a bootstrap value of $100 \%$.

Two colony forms of strain IMET $7848^{\mathrm{T}}$ exist. Initially only one form of colony, a rough one, was observed for strain IMET $7848^{\mathrm{T}}$ (Fig. 1A and 1D). During the detailed studies, smooth colonies occurred (Fig. 1B) together with the rough ones. To

FIG. 1. (A and B) Bright-field photomicrographs, taken without a cover slide, of growing, densely located colonies on the surface of $\mathrm{R}$ agar in petri dishes after 4 days of incubation at $28^{\circ} \mathrm{C}$. Bar $=50 \mu \mathrm{m}$. (A) Strain IMET 7848-r-rough colonies. (B) Strain IMET 7848-s—smooth colonies. (C) Phase-contrast photomicrograph of strain IMET $7848^{\mathrm{T}}$ cultivated for 2 days at $28^{\circ} \mathrm{C}$ in shaken culture with $\mathrm{R}$ medium. Cells occur singly, in pairs, in tetrads, or in little clusters. $\mathrm{Bar}=10 \mu \mathrm{m}$. (D) Phase-contrast photomicrograph of strain IMET $7848^{\mathrm{T}}$, taken after putting a cover slide onto growth on $\mathrm{R}$ agar in ring culture (diameter, 45 $\mathrm{mm}$; thickness of agar layer, $2.5 \mathrm{~mm}$ ) after 2 days of incubation at $28^{\circ} \mathrm{C}$. Cells are in regular packets which form large, irregular clusters. Bar $=10 \mu \mathrm{m}$. 


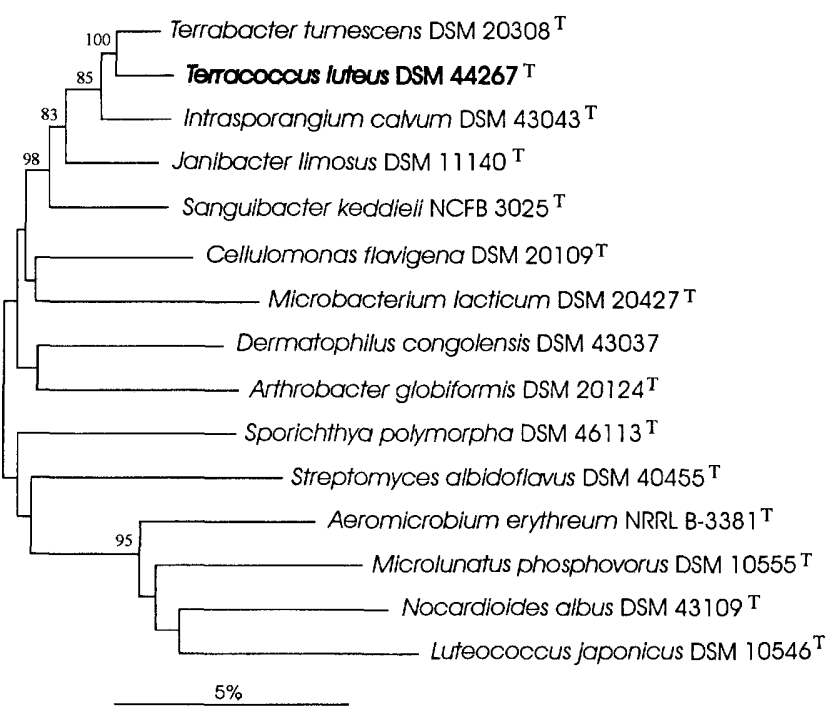

FIG. 2. 16S rDNA sequence-based phylogenetic dendrogram reconstructed from evolutionary distances by the neighbor-joining method (30). Scale bar, 5 inferred nucleotide substitutions per 100 nucleotides. Bootstrap values are represented by the numbers given at the branching points. Bootstrap values below $80 \%$ have been omitted. All organisms which are not members of the family Intrasporangiaceae serve as outgroup organisms for this family.

exclude the possibility of contamination, cells were isolated from both colony forms. The colony appearances of the resulting two strains proved to be stable on all applied media. After 5 days of incubation on $\mathrm{R}$ agar plates at $28^{\circ} \mathrm{C}$, the mats of the irregularly raised and lobed colonies of IMET 7848-r were dull while those of the circular, convex colonies of strain IMET 7848 -s were shiny, and those of strain IMET $7848^{\mathrm{T}}$, which exhibited both forms of colonies, were less shiny. There were no differences in color. The fatty acid profiles of the three strains were similar with regard to the quality and quantity of the components (Table 1). The partial 16S rDNA sequences of these strains were identical over the 5'-terminal 350 nucleotides. The DNA-DNA hybridization studies revealed DNA similarity values of $100 \%$ for the strain pair IMET $7848^{\mathrm{T}}$ and IMET 7848-r and for the strain pair IMET $7848^{\mathrm{T}}$ and IMET 7848 -s; i.e., the three strains, which originated from the same original culture, are identical from a taxonomic point of view. The organism under study has the capacity to develop rough as well as smooth colonies. The strains designated IMET 7848-r (for the rough form) and IMET 7848-s (for the smooth form) have been deposited at the DSMZ-German Collection of Microorganisms and Cell Cultures as DSM 44275 and DSM 44274 , respectively.

\section{DISCUSSION}

The phylogenetic analysis places strain IMET $7848^{\mathrm{T}}$ in a cluster together with $T$. tumescens and $I$. calvum (Fig. 2). T. tumescens was previously affiliated with the genera Arthrobacter and Pimelobacter (41), but the organism was shown to represent a separate phylogenetic lineage (2). I. calvum, originally (and mistakenly) thought to form sporangia (12), is a phylogenetic neighbor of $T$. tumescens (32). All of the other LL$\mathrm{A}_{2}$ pm-containing actinobacterial genera have been recognized as members of phylogenetic lineages which are separate from the Terrabacter-Intrasporangium lineage $(2,21,28,32,38,42$, 47).

Two recently described organisms, Sanguibacter keddieii (7) 
and $J$. limosus (20), were shown to be the nearest phylogenetic neighbors of $T$. tumescens and $I$. calvum (Fig. 2) (20, 38). The genera Intrasporangium, Terrabacter, and Sanguibacter were placed in the recently introduced family Intrasporangiaceae Rainey et al. (38), which was affiliated with the suborder $M i$ crococcineae (Prévot) Stackebrandt et al. of the order Actinomycetales (Buchanan) Stackebrandt et al. (38). According to the conception of the latter authors (38), the genus Janibacter (20) is also a member of the family Intrasporangiaceae. However, Sanguibacter keddieii and J. limosus differ significantly from strain IMET $7848^{\mathrm{T}}$ and its relatives, and from each other, with regard to phenotypic characteristics (Table 2). J. limosus contains meso-diaminopimelic acid in its directly cross-linked peptidoglycan and shows a complex fatty acid profile that includes straight-chain, iso-branched, saturated, and unsaturated fatty acids (Table 2). Sanguibacter keddieii has lysine as the diamino acid in the peptidoglycan, has predominately straightchain saturated fatty acids (Table 2), and has menaquinone MK- $9\left(\mathrm{H}_{4}\right)$ instead of menaquinone MK- $8\left(\mathrm{H}_{4}\right)$, which is present in strain IMET $7848^{\mathrm{T}}$ and in T. tumescens (Table 2).

Strain IMET $7848^{\mathrm{T}}, T$. tumescens, and $I$. calvum share an LL- $\mathrm{A}_{2}$ pm-containing peptidoglycan structure which is unique among the organisms of the class Actinobacteria Stackebrandt et al. (38) in that three glycine residues form the interpeptide bridge and another glycine residue is bound to the glutamic acid of the peptide subunit.

Since the published fatty acid profiles of one and the same strain frequently differ to some degree, e.g., the profiles reported for the type strain of T. tumescens $(4,25,32,41)$, the type strains of all LL- $\mathrm{A}_{2}$ pm-containing actinobacteria were examined under strictly standardized conditions in a previous study (32). The strains IMET $7848^{\mathrm{T}}$, IMET 7848-r, and IMET 7848 -s were subjected to the same procedure, and the results were compared with the previous ones (Table 1). T. tumescens, I. calvum, and strain IMET $7848^{\mathrm{T}}$ all have large amounts of 13-methyl tetradecanoic acid (iso- $\mathrm{C}_{15: 0}$ ). However, strain IMET $7848^{\mathrm{T}}$ differs significantly from both $T$. tumescens and I. calvum in having comparably large amounts of 12-methyl tetradecanoic acid (anteiso- $\mathrm{C}_{15: 0}$ ) and of hexadecanoic acid $\left(\mathrm{C}_{16: 0}\right)$ and a small amount of 14-methyl pentadecanoic acid (iso- $\mathrm{C}_{16: 0}$ ) and in the presence of five and the absence of two minor fatty acids, respectively (Table 1). Additionally, strain IMET $7848^{\mathrm{T}}$ differs from $T$. tumescens in having a small amount of 12-methyl tridecanoic acid (iso- $\mathrm{C}_{14}$ ) (Table 1). In other words, strain IMET $7848^{\mathrm{T}}$ is the most divergent organism with regard to fatty acid profile within the group consisting of the genera Terrabacter and Intrasporangium and strain IMET $7848^{\mathrm{T}}$. Concerning the polar lipids, strain IMET $7848^{\mathrm{T}}$ differs from $T$. tumescens in the presence of phosphatidylglycerol and the absence of unidentified phospholipids, and it differs from $I$. calvum in the presence of phosphatidylethanolamine and the absence of phosphatidylinositol mannosides (Table 2).

The growth cycle of $T$. tumescens includes cocci, irregular rods, initial branching, and fragmentation to cocci; i.e., the organism is typically coryneform. I. calvum develops an extended substrate mycelium which fragments into irregular propagative elements; i.e., the organism is typically nocardioform. Strain IMET $7848^{\mathrm{T}}$ is invariably coccoid and propagates by cell divisions in three perpendicular planes; i.e., it has a morphology and a life cycle like those of a sarcina (Fig. 1D).

The absence of susceptibility of strain IMET $7848^{\mathrm{T}}$ to any of the applied phages is not unexpected. It has been shown (27) that actinophages in general, and phages that are active against LL- $\mathrm{A}_{2}$ pm-containing actinomycetes in particular, are highly specific at the species or genus level or for closely related genera (6). The absence of phage susceptibility of strain IMET $7848^{\mathrm{T}}$, particularly to the $T$. tumescens phages $\mathrm{Tb} 1$ and $\mathrm{Tb} 2$, supports a separate taxonomic placement of strain IMET $7848^{\mathrm{T}}$.

The $73 \mathrm{~mol} \% \mathrm{G}+\mathrm{C}$ of the DNA of strain IMET $7848^{\mathrm{T}}$ corresponds to the values reported for T.tumescens (32) and differs from those of $I$. calvum by 5 mol\% (Table 2).

DNA-DNA hybridization was performed, since $16 \mathrm{~S}$ rDNA sequence homologies above $97.5 \%$ can correspond to DNADNA homology values that may be low or as high as $100 \%$ (36). In contrast to the delineation of species, for which DNADNA similarity values have been suggested to be higher than $70 \%$ (45), no guidelines have been published for the delineation of genera. In those cases in which discriminating chemotaxonomic and morphological properties that have been used in the discrimination of other actinobacterial genera are present, even moderate DNA-DNA similarity values, as shown in the present study, should not exclude the description of novel genera.

Taking into account the phylogenetic data, the DNA-DNA homology values, and the chemotaxonomic and morphological characteristics, including the growth cycles, there are two possibilities for classification of strain IMET $7848^{\mathrm{T}}$ and its relatives: (i) emendation of the genus Intrasporangium, reclassification of $T$. tumescens as Intrasporangium tumescens, and description of strain IMET $7848^{\mathrm{T}}$ as the type strain of a new species of the genus Intrasporangium; or (ii) maintenance of I. calvum and T. tumescens as representatives of individual genera and description of a new genus and new species for strain IMET $7848^{\mathrm{T}}$. Considering the present kind of taxonomic reasoning concerning the genus level within the order Actinomycetales, we assume the latter procedure to be the more adequate one. Additional isolates of relevant organisms will contribute to a better understanding of the relationships within this taxonomic area. However, these strains are presently not available. Thus, we propose that strain IMET 7848 be the type strain of the type species of a new genus, Terracoccus, which is described below.

Description of Terracoccus gen. nov. Terracoccus (Ter.ra. coc'cus. M. L. fem. n. terra, soil; Gr. masc. n. coccus, berry; M. L. masc. n. Terracoccus, coccus isolated from soil). Spherical to slightly ellipsoidal cells existing singly, in pairs, in tetrads, in irregular small clusters, or in more or less regular sarcinoid packets which may form large irregular clusters. Gram positive. Not acid fast. Nonmotile. No formation of spores.

Strictly aerobic. Chemoorganotrophic. Oxidase negative. Catalase positive.

The LL-diaminopimelic acid-containing peptidoglycan of group A3 $\gamma$ has three glycine residues as an interpeptide bridge and a fourth glycine residue bound to the $\alpha$-carboxyl group of the D-glutamic acid in position 2 of the peptide subunit. The major menaquinone is $\mathrm{MK}-8\left(\mathrm{H}_{4}\right)$. The fatty acid profile represents the iso, anteiso type with predominately 13-methyl tetradecanoic acid followed by 12-methyl tetradecanoic acid. Minor straight-chain fatty acids occur. The polar lipids are phosphatidylethanolamine, phosphatidylinositol, phosphatidylglycerol, and diphosphatidylglycerol. Mycolic acids are absent.

The DNA base composition is $73 \mathrm{~mol} \% \mathrm{G}+\mathrm{C}$.

The phylogenetic analysis relates this genus to the genera Terrabacter and Intrasporangium, which are, along with the genus Terracoccus, members of the family Intrasporangiaceae of the Actinomycetales suborder Micrococcineae. All signature nucleotides defined for the family Intrasporangiaceae are also found in strain IMET $7848^{\mathrm{T}}$ except for base pair positions 1134 to 1140 , in which strain IMET $7848^{\mathrm{T}}$ has an A-U rather than a G-C pair. 
The type species is Terracoccus luteus.

Description of Terracoccus luteus sp. nov. Terracoccus luteus (lu'te.us M. L. adj. luteus, yellow). The cells are spherical to slightly ellipsoidal, 0.7 to $1.3 \mu \mathrm{m}$ in diameter, gram positive, not acid fast, and nonmotile. The colonies, 0.05 to $2.0 \mathrm{~mm}$ in diameter, may be rough or smooth. Rough colonies are lobed and irregularly raised; smooth colonies are circular and convex. The cells of rough colonies are mostly arranged in more or less regular sarcinoid packets, which may form large irregular clusters. The cells of smooth colonies occur singly, in pairs, in tetrads, or in small irregular clusters.

Aerobic. Chemoorganotrophic. Oxidase negative. Catalase positive. Urease and $\mathrm{H}_{2} \mathrm{~S}$ are produced. Nitrate is not reduced to nitrite. Formation of acids from sugars and alcohols is not observed. Only a few of the tested compounds are utilized for growth, i.e., D-arabitol, gluconate, $N$-acetyl-D-glucosamine, myo-inositol, L-proline, succinate, sucrose, and D-turanose. Starch, casein, gelatin, esculin, and DNA are hydrolyzed; Tween 80 is not hydrolyzed. Sodium acetate, formate, aconitate, benzoate, citrate, hippurate, disodium succinate, and potassium tartrate are not utilized. Xanthine, hypoxanthine, adenine, and DL-tyrosine are not decomposed.

The LL- $\mathrm{A}_{2}$ pm-containing cell wall peptidoglycan contains three glycine residues as an interpeptide bridge and another glycine residue bound to glutamic acid of the peptide subunit. The major menaquinone is $\mathrm{MK}-8\left(\mathrm{H}_{4}\right)$. The major fatty acids are 13-methyl tetradecanoic acid and 12-methyl tetradecanoic acid. Diagnostic polar lipids are phosphatidylethanolamine and phosphatidylinositol. Mycolic acids are absent.

The DNA base composition is $73 \mathrm{~mol} \% \mathrm{G}+\mathrm{C}$.

The only known isolation site is soil at the water-soil interface of a duck pond at the island of Hiddensee, Germany.

The type strain is strain IMET 7848. It has been deposited in the DSMZ-German Collection of Microorganisms and Cell Cultures $\mathrm{GmbH}$ as strain DSM $44267^{\mathrm{T}}$.

\section{ACKNOWLEDGMENTS}

We are grateful to Eva Woitzik, Carmen Schult, Gabriele Pötter, and Jutta Burghardt for excellent technical assistance.

\section{REFERENCES}

1. Brosius, J., M. L. Palmer, P. J. Kennedy, and H. F. Noller. 1978. Complete nucleotide sequence of the 16S ribosomal RNA gene from Escherichia coli. Proc. Natl. Acad. Sci. USA 75:4801-4805.

2. Collins, M. D., M. Dorsch, and E. Stackebrandt. 1989. Transfer of Pimelobacter tumescens to Terrabacter gen. nov. as Terrabacter tumescens comb. nov. and of Pimelobacter jensenii to Nocardioides as Nocardioides jensenii comb. nov. Int. J. Syst. Bacteriol. 39:1-6.

3. Collins, M. D., and D. Jones. 1980. Lipids in the classification and identification of coryneform bacteria containing peptidoglycans based on 2,4-diaminobutyric acid. J. Appl. Bacteriol. 48:459-470.

4. Collins, M. D., R. M. Keddie, and R. M. Kroppenstedt. 1983. Lipid composition of Arthrobacter simplex, Arthrobacter tumescens and possibly related taxa. Syst. Appl. Microbiol. 4:18-26.

5. DeSoete, G. 1983. A least square algorithm for fitting additive trees to proximity data. Psychometrika 48:621-626.

6. Deutsche Sammlung von Mikroorganismen und Zellkulturen. 1993. Catalogue of strains, 5th ed. Deutsche Sammlung von Mikroorganismen und Zellkulturen GmbH, Braunschweig, Germany.

7. Fernández-Garayzábal, J. F., L. Dominguez, C. Pascual, D. Jones, and M. D. Collins. 1995. Phenotypic and phylogenetic characterization of some unknown coryneform bacteria isolated from bovine blood and milk: description of Sanguibacter gen. nov. Lett. Appl. Microbiol. 20:69-75.

8. Gordon, R. E., D. A. Barnett, J. E. Handerhan, and C. H.-N. Pang. 1974 Nocardia coeliaca, Nocardia autotrophica, and the nocardin strain. Int. J. Syst. Bacteriol. 24:54-63.

9. Gordon, R. E., and J. M. Mihm. 1957. A comparative study of some strains received as nocardiae. $\mathbf{J}$. Bacteriol. 73:15-27.

10. Groth, I., P. Schumann, N. Weiss, K. Martin, and F. A. Rainey, 1996 Agrococcus jenensis gen. nov., sp. nov., a new genus of actinomycetes with diaminobutyric acid in the cell wall. Int. J. Syst. Bacteriol. 46:234-239.

11. Jukes, T. H., and C. R. Cantor. 1969. Evolution of protein molecules, p. 
21-132. In H. N. Munro (ed.), Mammalian protein metabolism. Academic Press, New York, N.Y.

12. Kalakoutskii, L. V., I. P. Kirillova, and N. A. Krassilnikov. 1967. A new genus of the Actinomycetales-Intrasporangium gen. nov. J. Gen. Microbiol. 48:79-85.

13. Kämpfer, P., W. Dott, and R. M. Kroppenstedt. 1990. Numerical classifica tion and identification of some nocardioform bacteria. J. Gen. Appl. Microbiol. 36:309-331.

14. Kirchhoff, H., C. Maass, M. Runge, B. Franz, R. Schmidt, H. Quentmeier, and P. F. Mühlradt. 1992. Tetrazolium [3-(4,5-Dimethylthiazol-2-yl)-2,5 diphenyltetrazoliumbromide] reduction by mycoplasmas. Int. J. Syst. Bacteriol. 42:506-508.

15. Klatte, S., K.-D. Jahnke, R. M. Kroppenstedt, F. Rainey, and E. Stackebrandt. 1994. Rhodococcus luteus is a later subjective synonym of Rhodococcus fascians. Int. J. Syst. Bacteriol. 44:627-630.

16. Lányi, B. 1987. Classical and rapid identification methods for medically important bacteria, p. 1-67. In R. R. Colwell and R. Grigorova (ed.), Methods in microbiology, vol. 19. Academic Press, London, United Kingdom.

17. Lechevalier, M. P., H. Lechevalier, and P. E. Holbert. 1968. Sporichthya, un nouveau genre de Streptomycetaceae. Ann. Inst. Pasteur (Paris) 114:277-286.

18. MacKenzie, S. L. 1987. Gas chromatographic analysis of amino acids as the N-heptafluorobutyryl isobutyl esters. J. Assoc. Off. Anal. Chem. 70:151-160.

19. Maidak, B. L., N. Larsen, M. J. McCaughey, R. Overbeek, G. J. Olsen, K Fogel, J. Blandy, and C. R. Woese. 1994. The Ribosomal Database Project. Nucleic Acids Res. 22:3485-3487.

20. Martin, K., P. Schumann, F. A. Rainey, B. Schuetze, and I. Groth. 1997 Janibacter limosus gen. nov., sp. nov., a new actinomycete with meso-diaminopimelic acid in the cell wall. Int. J. Syst. Bacteriol. 47:529-534.

21. Miller, E. S., C. R. Woese, and S. Brenner. 1991. Description of the erythromycin-producing bacterium Arthrobacter sp. strain NRRL B-3381 as Aeromicrobium erythreum gen. nov., sp. nov. Int. J. Syst. Bacteriol. 41:363368.

22. Minnikin, D. E., L. Alshamaony, and M. Goodfellow. 1975. Differentiation of Mycobacterium, Nocardia, and related taxa by thin-layer chromatographic analysis of whole-organism methanolysates. J. Gen. Microbiol. 88:200-204.

23. Minnikin, D. E., M. D. Collins, and M. Goodfellow. 1979. Fatty acid and polar lipid composition in the classification of Cellulomonas, Oerskovia and related taxa. J. Appl. Bacteriol, 47:87-95.

24. Nakamura, K., A. Hiraishi, Y. Yoshimi, M. Kawaharasaki, K. Masuda, and Y. Kamagata. 1995. Microlunatus phosphovorus gen. nov., sp. nov., a new gram-positive polyphosphate-accumulating bacterium isolated from activated sludge. Int. J. Syst. Bacteriol. 45:17-22.

25. O'Donnell, A. G., M. Goodfellow, and D. E. Minnikin. 1982. Lipids in the classification of Nocardioides: reclassification of Arthrobacter simplex (Jensen) Lochhead in the genus Nocardioides (Prauser) emend. O'Donnell et al. as Nocardioides simplex comb. nov. Arch. Microbiol. 133:323-329.

26. Prauser, H. 1976. Nocardioides, a new genus of the order Actinomycetales. Int. J. Syst. Bacteriol. 26:58-65.

27. Prauser, H. 1984. Phage host ranges in the classification and identification of gram-positive branched and related bacteria, p. 617-633. In L. Ortiz-Ortiz, L. F. Bojalil, and V. Yakoleff (ed.), Biological, biochemical, and biomedical aspects of actinomycetes. Academic Press, Orlando, Fla

28. Rainey, F. A., P. Schumann, H. Prauser, R. Toalster, and E. Stackebrandt. 1993. Sporichthya polymorpha represents a novel line of descent within the order Actinomycetales. FEMS Microbiol. Lett. 109:263-268.

29. Rainey, F. A., N. Ward-Rainey, R. M. Kroppenstedt, and E. Stackebrandt 1996. The genus Nocardiopsis represents a phylogenetically coherent taxon and a distinct actinomycete lineage: proposal of Nocardiopsaceae fam. nov. Int. J. Syst. Bacteriol. 46:1088-1092.

30. Saitou, N., and M. Nei. 1987. The neighbor-joining method: a new method for reconstructing phylogenetic trees. Mol. Biol. Evol. 4:406-425.

31. Schleifer, K. H., and O. Kandler. 1972. Peptidoglycan types of bacterial cell walls and their taxonomic implications. Bacteriol. Rev. 36:407-477.

32. Schumann, P., H. Prauser, F. A. Rainey, E. Stackebrandt, and P. Hirsch. 1997. Friedmanniella antarctica gen. nov., sp. nov., an LL-diaminopimelic acid-containing actinomycete from antarctic sandstone. Int. J. Syst. Bacteriol. 47:278-283.

33. Shirling, E. B., and D. Gottlieb. 1966. Methods for characterization of Streptomyces species. Int. J. Syst. Bacteriol. 16:313-340.

34. Smibert, R. M., and N. R. Krieg. 1981. General characterization, p. 409-443. In P. Gerhardt, R. G. E. Murray, R. N. Costilow, E. W. Nester, W. A. Wood N. R. Krieg, and G. B. Phillips (ed.), Manual of methods for general bacteriology. American Society for Microbiology, Washington, D.C.

35. Stackebrandt, E. 1981-1982. What is an actinomycete? Actinomycetes 16: $132-138$.

36. Stackebrandt, E., and B. M. Goebel. 1994. Taxonomic note: a place for DNA-DNA reassociation and 16S rRNA sequence analysis in the present species definition in bacteriology. Int. J. Syst. Bacteriol. 44:846-849.

37. Stackebrandt, E., C. Koch, O. Gvozdiak, and P. Schumann. 1995. Taxonomic dissection of the genus Micrococcus: Kocuria gen. nov., Nesterenkonia gen. nov., Kytococcus gen. nov., Dermacoccus gen. nov., and Micrococcus Cohn 1872 gen. emend. Int. J. Syst. Bacteriol. 45:682-692.

38. Stackebrandt, E., F. A. Rainey, and N. L. Ward-Rainey. 1997. Proposal for a new hierarchic classification system, Actinobacteria classis nov. Int. J. Syst. Bacteriol. 47:479-491.

39. Staley, J. T. 1968. Prosthecomicrobium and Ancalomicrobium: new prosthecate freshwater bacteria. J. Bacteriol. 95:1921-1942.

40. Stead, D. E., J. E. Sellwood, J. Wilson, and I. Viney. 1992. Evaluation of a commercial identification system based on fatty acid profiles for rapid, accurate identification of plant pathogenic bacteria. J. Appl. Bacteriol. 72:315321

41. Suzuki, K.-I., and K. Komagata. 1983. Pimelobacter gen. nov., a new genus of coryneform bacteria with LL-diaminopimelic acid in the cell wall. J. Gen. Microbiol. 29:59-71.

42. Tamura, T., M. Takeuchi, and A. Yokota. 1994. Luteococcus japonicus gen. nov., a new gram-positive coccus with LL-diaminopimelic acid in the cell wall. Int. J. Syst. Bacteriol. 44:348-356.

43. Uchida, K., and K. Aida. 1984. An improved method for the glycolate test for simple identification of the acyl type of bacterial cell walls. J. Gen. Appl. Microbiol. 30:131-134

44. Waksman, S. A., and A. T. Henrici. 1943. The nomenclature and classification of the actinomycetes. J. Bacteriol. 46:337-341.

45. Wayne, L. G., D. J. Brenner, R. R. Colwell, P. A. D. Grimont, O. Kandler, M. I. Krichevsky, L. H. Moore, W. E. C. Moore, R. G. E. Murray, E. Stackebrandt, M. P. Starr, and H. G. Trüper. 1987. Report of the ad hoc committee on reconciliation of approaches to bacterial systematics. Int. J. Syst. Bacteriol. 37:463-464.

46. Yamada, K., and K. Komagata. 1972. Taxonomic studies on coryneform bacteria. IV. Morphological, cultural, biochemical, and physiological characteristics. J. Gen. Appl. Microbiol. 18:399-416.

47. Yokota, A., T. Tamura, M. Takeuchi, N. Weiss, and E. Stackebrandt. 1994. Transfer of Propionibacterium innocuum Pitcher and Collins 1991 to Propioniferax gen. nov. as Propioniferax innocua comb. nov. Int. J. Syst. Bacteriol. 44:579-582. 